\title{
The pedagogical logics of arts rich schools: a Bourdieusian analysis
}

Pat Thomson, Christine Hall, Lexi Earl, Corinna Geppert

School of Education, The University of Nottingham

Accepted for publication in the British Journal of Sociology of Education, November 26, 2018.

\begin{abstract}
The arts are under threat in English schools. But some schools and teachers work against the trend. To understand how they continue to offer rich arts experiences to students, we bring Bourdieusian thinking to arts teacher practices that were common across the thirty secondary schools we studied for three years. In addition to a flexible approach to the curriculum which encouraged independence, intellectual challenge and risk -taking, teachers also engaged in arts brokerage embodiment of arts engagement, ensuring students regularly visit cultural events/ institutions, using local cultural resources, organising visits from artists/cultural organisations, enabling students to exhibit and perform for wider audiences, connecting students with arts workplaces, and enhancing community arts participation. We approach this as a logic of practice associated with arts broker dis/positions drawn from teachers simultaneously occupying two chiasmatic fields - art and education.
\end{abstract}

How do teachers and schools maintain practices that go against the grain of current policy? Where do their oppositional ideas come from and how are they maintained? These questions sit at the heart of this paper, which brings Bourdieusian thinking to a study of arts education. The paper addresses what are sometimes called 'cross field effects', the ways in which doxa and practices from one field are taken up in another. Rather than use this approach, we work with the notion of field positionality, and the phenomenon of dual or multiple occupancy. We consider the implications of dual positionality for logics of practice and agent disposition through an exploration of data drawn from a three year study of arts education in thirty English secondary schools. We speculate about the reproductive and counter reproductive possibilities of these dual field logics and teacher dispositions.

We begin the paper with a preliminary discussion of our approach to Bourdieu, and move to discuss the wider field of education policy with particular reference to the arts. We then introduce our data referring to the homologies and autonomies of similarly positioned schools, students and teachers. We conclude with a discussion of reproduction and the potentials for change in the field. First of all, we outline the overall research project from which this analysis is derived.

\section{The TALE project}

Tracking Arts Learning and Engagement (TALE) is a three-year longitudinal research project funded by Arts Council England, a partnership between the University of Nottingham, Tate (School and Teachers team), and The Royal Shakespeare Company (Education). The project investigates how teachers take up professional learning offered by arts organisations and make it pedagogical in their specific context, and what their students experience and learn. 
We studied secondary schools which bucked the current trend of arts education policy (explained later). We wanted to find out what they did differently, why they still focused on the arts and how this was manifest in the wider school and classrooms. We hoped that this would tell us something about the benefits of an arts-rich education. The study was not designed as a representative sample; fifteen schools were nominated by the RSC and fifteen by TATE because of the long-term involvement of either a teacher (TATE) or school (RSC). However, as it turned out, the schools roughly match the socioeconomic spread and balance of the state funded system. The schools were geographically spread across the country. They included: three special schools, one independent school, three single sex schools and the same proportion of academies as the national ratio of two thirds of all secondary schools'.

We followed 63 teachers over three years. Each year we visited the schools for between one to three days and asked Teachers 1 and 2 questions about their own participation in the arts, both recreational and professional; their perception of benefits to their students and to themselves; professional development and work related benefits and ambitions. We examined their rooms, their teaching programmes and pupil work. Where possible, we watched them teach. We tracked pupils across three years in each of the schools and administered a survey about arts participation to all students in years 10-13.

This paper draws primarily on data from teacher interviews from Year One (2015/16) and Year Two $(2016 / 17)$ of the project. In total, 52 teachers were interviewed in Year One and 62 in Year Two (40 teachers were interviewed twice). Of these, 40 had attended professional development with either the Tate or the RSC. We also draw on the survey, field-notes from lesson observations, informal conversations, teacher and school social media accounts and in two cases, documented conversations at Tate Summer School 2016. This corpus has been analysed thematically; this paper reports on one theme - teachers' encouragement of and support for students' participation in the arts in and out of school.

\section{Fields, dis/positions and agents}

Bourdieu suggested that the social world could be understood through the notion of social fields (Bourdieu 1977, 1990). Field is a heuristic which can be used analytically to better understand the ways in which, for example, education (Bourdieu 1988; Bourdieu and Passeron 1977, 1979), science (Bourdieu 1975), art (Bourdieu 1991) and literature (Bourdieu 1992) produce and reproduce variously inequitable social relations, practices and truths. A field is social, cultural and material and is occupied by people and things which act in relation to each other. In this paper, we are concerned with two fields, education and art.

Fields are populated by agents (actors) who occupy social positions (in education, we might think of positions such as headteachers, teachers, business managers and so on). Agents are continually engaged in field practices, and their actions generally follow a dominant logic designed to acquire capitals (social, cultural, symbolic and economic) through which they can advance, or at least maintain their position relative to others (Bourdieu 1977).

However, even though fields are reproductive they are also not uniform. They are chiasmatic - that is, they are engaged in continued struggles for position. Within any field, there are agents acting counter to dominant modes; oppositional doxa (beliefs and truths) support resistant and counter status-quo practices. Change in a field is thus not only possible but inevitable; fields are not homogenous, but are continually conflicted - this lack of uniformity/conformity is why change occurs. Bourdieu's study of the field of European art (Bourdieu 1991), for instance, documented how an art avant-garde eventually gained dominance in the field: practices that were once oppositional

\footnotetext{
${ }^{1}$ https://www.gov.uk/government/publications/open-academies-and-academy-projects-indevelopment ( accessed August 2018).
} 
became dominant in part through a new art field economics homologous with the wider field of capital.

Field relations are hierarchical, both vertically and horizontally - so a head-teacher has more status and more highly valued capitals than a teacher (vertical), and a head in a pupil referral unit has lower status and less highly valued capitals than a headteacher of a selective grammar school (horizontal). While fields operate in similar ways (they are homologous), in that they are concerned with the logics of differentiated positions, each has its own particular set of capitals and its own ways of explaining their value (doxa). Doxa often misrecognise the ways in which their application in practice produces and reproduces inequitable hierarchies (Bourdieu 1998).

Agents learn how to act in the particular fields in which they have a position. This learning becomes a kind of embodied second nature (Bourdieu called this habitus), and agency - what agents do - can be understood as a continued interaction between the embodied understandings of action and temporal/spatial contexts. Habitus, understood as a constellation of dispositions, is formed in the ongoing interactions between field, capitals and field positions. Agents are disposed, by virtue of who they are, where they have been, and their life experience in positions, to act and be in particular ways. It is an illusion, Bourdieu suggests, to think that any one actor is an individual: we are all socially situated and act in relation to others in the field (Bourdieu 1987). Bourdieu notes that field change is often driven by agents who experience a deep rift between their habitus and the dominant strategies in the field. It is possible for such agents to act in ways counter to the dominant logics of practice and/or doxa of the field in which they occupy a position, drawing on subjugated strategies and capitals. In chiasmatic fields we can therefore expect to find positions and agents that act according to different logics which are opposed to the dominant.

Bourdieu envisaged a relationship between fields. He suggested that the education field prepared agents for positions in all other fields. Thus, arts teachers in part prepare students taking arts subjects by ensuring that they have the relevant capitals, doxa and dispositions relevant for the art field and others. But Bourdieu also argued that agents can and do occupy more than one field over their lifetime, and often more than one field at the same time. This is the key to our analysis here.

Dual positioning offers interesting possibilities for cross-field flows, relationships and effects. We are interested in agents who occupy a position in two fields at once - education and the arts. However, beyond cleft habitus, the conflict between primary habitus and later field dispositions (Ingram and Abrahams 2016; Stahl 2013), and the notion of 'cross field effects' (Lingard and Rawolle 2004, 2013), we have to date found very little discussion of simultaneous field positionality in the scholarly literatures. We have also chosen to speak of disposition, rather than habitus (see Reay 2004), as the practices that we are discussing emanate from a position.

We now move to our analysis, beginning, as per a Bourdieusian approach (Bourdieu and Wacquant 1992, 104-5), with the field and field positions.

\section{Education and the arts in English schools: the field}

The field of education in England has been subject to reconstruction steered by the political field. The dimensions of this change are well known. The education field has been politically reconstructed so that it much more closely resembles the dominant mode of the economic field, the market. There are new players and positions - academy trusts and free schools, commercial interests and philanthropists, regional commissioners, highly paid executive headteachers - and old players with reduced powers and strategies - local authorities, parents and school governors (Ball and Junemann 2012; Ball 2018). These changes have not introduced diversity nor changed the reproduction of 
privilege: indeed the middle class continues to benefit most from school choice and class continues to be a key to students' attainment (Power et al. 2002; Ball 2003; Gorard 2018). These positional changes sit alongside changed wider social and economic conditions - a rise in the school leaving age, an increase in the overall number of children in the school system, a collapse of the youth labour market and a reduction in school funding in real terms. Schools are arguably expected to 'mop up' more young people and in conditions that force them to do so at reduced costs in order to maintain position. They must educate more students, but maintain the sorting and selecting processes characteristic of the field.

The curriculum - the capitals which count in schooling - has not been exempt from changes. School based assessment has given way to exams with new grading systems which more finely sort and select those students best 'fitted' for 'terminal' testing. A revised national curriculum focuses on the elite cultural capitals embedded in a 'restorationist' knowledge-based approach (Apple 2001). The field status of schools is now determined by how well they perform in a selection of subjects known as the English Baccalaureate; these exclude the arts. Universities too have changed their preferred list of 'facilitating subjects' for university entrance to exclude the arts.

In this context it is perhaps not surprising that choosing to keep the arts, their subordination in the hierarchy of subjects confirmed and strengthened, is proving to be an increasingly unattractive move for schools and students alike. Enrolments in all arts subjects in state-funded schools have fallen, less time is given to the arts in primary and junior secondary schools and arts teacher numbers are falling (Johnes 2017). This trend is not apparent in independent schools where parents with sufficient finances are able to ensure that their children engage in the arts out of school time. For the vast majority of schools however the arts are increasingly a marginal curriculum offering. Of course, schools that are working for market distinction via another subject cluster, such as science, may use images of arts engagement in their marketing portfolios (Wilkins 2011) while, at the same time, they are actively discouraging students from taking arts subjects.

Not all schools shun the arts. Some retain the arts, as our research attests. One explanation for continued commitment to the arts is that in a marketised field a school can use the arts as a marker of distinction to distinguish it from competitors. This is particularly important for schools seeking to attract middle class parents: the school is able to demonstrate that it works to reproduce and extend the capitals that students already have.

Not all students shun the arts. In the context of competitive higher education enrolment, some students are still able to use arts capitals to advantage in university programmes where an interview and/or portfolio are important. They can show themselves to be culturally active and socially aware by virtue of their engagement with local and national arts organisations, events and projects. Even where the arts are no longer officially part of the admission process, they still play an informal role in elite universities and in arts specific programmes. Students who apply to universities lower in the hierarchy and who do not have interviews but are selected solely on exam results cannot generally use their arts participation in the same way; such courses and institutions include higher proportions of working class students because of the strong homology between upper middle class position and elite university enrolment (Reay, David, and Ball 2005).

But logics other than reproduction co-exist in the field even if they are not dominant. Even though we take as a given that schools are reproductive, we hoped to probe the tensions that existed around the arts. Our data led us to consider in particular the question of field position.

\section{The arts rich school as a field position}

We have already explained that the schools that we researched had teachers in them who had long term relationships with either RSC or TATE. When we came to examine the schools in which the 
teachers were located we saw that they were also mostly schools that were relatively successful in maintaining their position in the field. In 2017, the middle year of the project, 7 of the schools had 'outstanding' Ofsted ratings, 7 were 'requiring improvement', 2 were 'inadequate' and the remainder were 'good'. These inspection judgments were made on the basis of test and exam results, and for those outstanding schools that had not recently been inspected, this included the arts at the GCSE level rather than the new E Bacc.

The majority of our schools shared some common features. Our document analysis and interviews with senior leaders showed that most of the schools offered a wide selection of arts subjects from Years 7-11, had a sizeable complement of specialist arts teachers, devoted significant timetable allocations to the arts, offered a range of choice at GCSE and had included oversight of the arts in their middle and sometime senior management team. Their arts offer was integral to their interpretation of 'good' schooling and a 'broad and balanced' education. This commitment to the arts was long term; generally they had been committed to the arts for many years, although many were finding it difficult with new funding cuts. The arts were integral to way that they promoted themselves but also an essential part of their identity and their semiotic, management and pedagogical systems.

Because these practices were similar despite the schools themselves being geographically and socioeconomically diverse, we concluded that most of the research schools occupied a particular position in the field, that of 'the arts rich school'. The arts were a marker of field distinction. Regardless of whether they were in the outstanding, good, improving or inadequate cluster of positions, the majority of our schools were distinguished by the practice logics of arts engagement.

As Bourdieu noted, any position is itself a field and one would expect to find homologous logics at work in the internal field. We might for instance expect to see something different about the agents in the arts rich school position. And we did. Here, we briefly indicate key results related to students.

In interviews students studying the arts routinely told us that they chose the arts because of what it offered them in the future - not a job but rather a way of being in and making a worthwhile life. They also told us that the arts were different from their other subjects; choosing an arts subject meant they undertook long term ambitious projects, worked independently, had more positive relationships with their arts teachers, experienced the sense of well-being and self-belief that results from hard work and meeting intellectual and practical challenges (Thomson et al. 2019). Despite the diversity of schools and students, it was apparent from our thematised analysis that a particular pedagogical approach was in play across our sites. This is congruent with the notion of the arts rich school as a position - the arts could be expected to share common pedagogical practices. However, a minority of teachers practice was similar despite them being in schools that were less arts-inclined.

The TALE survey revealed further evidence of a shared and particular pedagogical logic in the schools. The survey asked students about their cultural participation in and out of school. We were particularly interested in making a comparison between TALE students and national data on cultural participation collected through the national Taking Part survey, an annual government survey of cultural participation. We were able to compare 14/15 year olds from our study with those in Taking Part, controlling for gender as our sample had more girls than the national data. The results showed that students in TALE schools participated in out of school arts and cultural activities more than the national representative sample of their peers (Thomson et al. 2018). This adds further weight to the notion that the arts rich schools occupy a position, through which students are disposed to act in particular ways. An arts participation disposition - what some students choosing arts identified as learning arts as a way of life - is formed for more students than is found in the field more generally. It is important to note that a quarter of the students also told us that the school and had introduced 
them to the arts and one third told us that they depended on their school for arts engagement. (We refer to this again at the end of the paper.)

The actions of teachers are key to both the pedagogical logics of the arts rich school and the formation of an arts participation disposition in students. Our study shows a great deal about common aspects of the arts teachers' practice. We now go on to describe two key shared practices, followed by a discussion of these as dispositional, the result of dual field occupancy.

\section{The arts broker teacher position}

When discussing positions and the agents that occupy them it is helpful to identity some common characteristics, avoiding what Bourdieu called the 'biographical illusion', the presentation of people as if they are extracted from the field of power and from specific fields through which they have passed. We therefore focus on two key inter-related practices common to teachers in our study, regardless of whether they were working with performing or visual arts and regardless of the school they were in. Following our previous argument about position, we understand these as positional strategies situated with the arts rich school field position. The practices were (1) working with a 'students as artists' perspective, and (2) arts brokerage.

\section{(1) A 'students as artists' perspective}

Students in English schools are very often treated as 'becomings'; teaching is organised around future exams, course entry and jobs. In contrast, the visual and performing arts teachers that we observed and interviewed started from the position that students were, in their rooms, present 'beings', already artists, as this quotation suggests:

I always say to my students right at the beginning that when they walk through the doors of my classroom they are walking into a rehearsal studio and they are very much young actors and we will be creating theatre together. I expect them to be evaluative actors who can look back and also comment on other people's work in a supportive environment."

Thus, in performing arts, supported by the RSC, teachers used professional practices - ensemble (Neelands 2009), rehearsal room (Franks et al. 2014). They engaged students in dramaturgical discussion about possible interpretations and directorial decisions about the translation of ideas into action and staging. In the visual arts, teachers worked through topic-focused modules which offered students the opportunity to work separately and together to design and complete ambitious projects. Such visual arts projects extended students' interests and prior understandings, referred to and intertextually used work of other artists, and required continuous documentation of their thinking and experimentation.

In both arts forms students were able to bring the 'texts of their lives' (Fecho 2011) into the classroom, connect activities with 'big ideas' and bring knowledges from other disciplines to the realisation of their projects (Beane 1995). The teachers carefully steered learning, providing leads to relevant intellectual and material resources, setting milestones, challenging students to take risks and make mistakes from which they could learn. They used whole class instruction and skills oriented and practice exercises to support the development of understanding, knowledge, expertise and craft. Senior students were expected to use their initiative, work independently, research extensively and to explain their artistic choices. Teachers thus had to have deep knowledge of each students' interests, strengths and weaknesses in order to 'negotiate' the curriculum (Boomer et al. 1992 ) in ways that pushed students to do more than they had originally imagined. In so doing, teachers used their disciplinary lexicon, and norms and expectations derived not only from the education curriculum frameworks, but also from professional theatre and visual arts arenas. 


\section{(2) Arts brokerage}

A broker is usually understood as someone who acts as an intermediary in negotiations, they 'broker a deal'. A broker is a go-between, a mediator, bringing together people or things or people and things who, without them, might not have met each other. The notion of brokerage is used in academic writing literatures to describe the role and actions of a knowledgeable, and usually senior, academic who mentors and supports the publication activities of younger colleagues (Thomson and Kamler 2013), or those new to English language publication (Lillis and Curry 2010). The senior colleague has expertise and experience that they share. The term cultural brokerage is usually applied to people who work in intercultural settings: it has for example been used in health (Jezewski 1995; Willis 1999) and in education (Wyatt 1978-79) to describe nurses and teachers who mediate across cultural boundaries in order to prevent misunderstanding and discrimination and promote mutual and reciprocal learning. In this context the notion of brokering culture has been critiqued for lack of reciprocity and implicit paternalism and colonialism (McKinley 2001).

Arts broker teachers have expertise and experience in the arts. They provide mentoring and support to students to engage with the arts and encourage students to cross borders into arts territories they do not know. However, they do not assume a lower status for the students' own arts interests, experiences, practices and knowledges. They opt for active social pedagogies of encouragement, enthusiasm, explanation and support. TALE teachers saw the arts as vital to a broad and balanced curriculum. They also saw the arts as integral to both education and everyday life. The TALE teachers who acted as arts brokers generally used all, or a majority, of the following seven strategies:

(a) Teachers embodied what it means to be culturally engaged

Teachers in our study were deeply engaged in the arts. They regularly attended a wide range of events, exhibitions and performances. Some also directed, acted, made and showed their own work. They were part of local, regional and national artistic networks. Their art field capitals include knowledge of a wide range of artists, works, genres, galleries, theatres, festivals and studios and thus, some understandings about the visual and performing arts markets. Teachers shared their outof-school experiences and knowledge with their students, routinely talking about what they had seen and done and what they read, creating an ongoing classroom conversation. Their experiences and arts knowledges were resources used to make the formal curriculum current.

(b) Teachers ensured students regularly visited local and national cultural events, institutions and organisations

Despite the arduous risk assessment exercises now demanded of schools, and within the restrictions of school funding, teachers saw visits to cultural institutions as integral to their classroom programme, not as a treat or a special occasion. Whether it was a trip to a local theatre to view a play for Drama or English, or to a national gallery to look at art work, teachers saw visits as offering a range of benefits, which included changed social relations with peers and understandings about work, accessing a shared culture and new levels of aesthetic experience. Visits extended students' horizons and offered the opportunity not only to see and understand a new place but also to see their own place afresh..

(c) Teachers actively sought out and used students' and communities' cultural resources

It was important to arts broker teachers that students did not get the idea that the only arts worth engaging with were those that they did not have ready access to. Arts broker teachers understood neighbourhood and students' arts practices as cultural participation and as learning resources. Visual art teachers filled their rooms, corridors, and often gallery spaces created within the wider school, with students' art work; the visible intertextuality (references to a wide range of advertising, youth cultures 
and current events) in these works attested to the inclusive approach taken by their teachers. Performing arts teachers encouraged discussion of and improvisation around community events and concerns and pressing social issues in the media. These often appeared in interpretations of canonical texts, such as Shakespeare.

(d) Teachers organised artists and cultural organisations to visit their schools

Despite the expense, arts broker teachers saw the importance for students of regular contact with professional artists and their work. Artists brought a range of teachable opportunities, ranging from the substantive topic of the event/practice and meaningful encounters with working professionals, to consideration of disciplinary norms, habits, ways of working and languages. By finding ways to connect with local artists and arts organisations, teachers actively renegotiated symbolic institutional borders to make the school permeable and bring new practices and experiences to students. Teachers took advantage of travelling theatre productions and workshops specifically aimed at schools, welcomed artists-in-residence to create artwork and engage with students. Visiting artists were often asked to make work with students about local lives and the local environment.

Extra-curricular and the formal curriculum were blurred through visits, everyday life and school joined together, and the substantive arts experience formed a bridge between home and school.

(e) Teachers provided opportunities for students to exhibit and perform their work for wider audiences

Performing and exhibiting - students made work not simply for assessment but for wider and public audiences - created an inter-linked set of learning opportunities. Students' immediate families were able to attend/view and understand what their children are doing, and perhaps become more connected to the school (see above). Other faculties in the school saw and understood what happens in the arts; their value was on view. Opportunities for joint work with local and national arts organisations allowed students to experience arts disciplinary processes and norms in semi-professional contexts. Through exhibitions and performance, students moved from the position of consumer to that of producer. They learnt that artists make work which asks and receives audience response; communicates ideas (some of which might be highly critical of the status quo); is marketed and sold. They began to understand that the arts are 'institutional' - theatres and galleries have their own particular modes of operation, places in the market and so on (positions in the art field.) Teachers used exhibition and performance as occasions to instil professional norms (see above).

\section{(f) Teachers connected students to arts workplaces}

Teachers often used their own personal networks (social capital) and went out of their way to build new connections that could bring their students into contact with the arts and culture industry. They saw the obvious connection between work experience and choosing to study an arts subject. But they generally viewed workplace programmes not as suggesting possible career pathways to students, but more as showing students what work in the arts, other than teaching, could be like. Arts workplaces are steeped in (often inexplicit) professional capitals - ways of talking and doing things. As well as the more general work-related acts of meeting deadlines, being accountable and working collaboratively, arts workplaces generally have ways of allocating time and space for idea generation, exploration and critical evaluative 'quality' conversations. The dispositional and the doxic were available for student apprentices. They could learn how to behave, speak, think and 'play the game' of the arts.

(g) Teachers worked to enhance arts participation in their communities

Bringing theatre companies into school to perform created a cultural experience for the local community. Teachers in rural communities, or in communities without well-developed theatre cultures, saw this as an important access strategy. However, teachers often went much further. Teachers were often engaged in local arts initiatives which would bring substantial benefits to their schools and their cities and towns. Engagement with community arts development was not divorced 
from school; students clearly benefited from enhanced arts activities in their area. Nor was it removed from the arts broker teachers' own lives; they and their families also benefited from a wider range of local arts. Teachers brought an understanding that the arts involve 'place-making' practices, they enhance local social bonds and build and strengthen social and cultural capital.

In sum, the arts broker teacher did more than simply organise the occasional excursion or inviting artists to give talks. They made a wide range of capitals - elite and vernacular arts and cultures, various genres and events, disciplinary norms and professional practices, new networks - available to students. They also embodied, through their own everyday arts passions and pastimes, an arts world disposition - what engaging with the arts does and means, as we now explain.

\section{Dual field occupancy and an arts world dis/position}

We now attend to the logics of the pedagogical practices of the arts broker teacher. We argue that both seeing students as artists and arts brokerage practice stem from a conjunction of arts and school field positionality which creates an arts world disposition.

We asked teachers in our study about their life experiences in the arts. All of them told us about childhoods in which the arts were important to them. Even though their primary class habitus varied from working class to middle class strata, all of the teachers had had ongoing access to various arts and cultural practices at home and at school. They had continued this interest through education: the teachers associated with the RSC had generally studied literature and/or drama, and the visual arts teachers had gone to art school and/or studied art history. They maintained an active interest in arts and culture outside of their classroom. As noted, many had some kind of independent arts practice apart from school and thus occupied a place in the arts field. They had capitals, dispositions and doxa in common with full-time artists.

We suggest that the arts broker teacher with a dual position has a 'hybridised' (Adams 2006) arts world disposition, that is, they take as natural and right the practice of making pedagogies from embedded and embodied understandings of the games of the arts world. They adhere to art field doxa of the importance of arts activities and work to produce arts capitals and an arts disposition, just like their own, in their students. Of course, the arts teachers in our study are not the only agents in the field to occupy positions in both education and art fields. Many visual and performing arts teachers do. We have explored the practices of arts teachers in other projects (Thomson, Jones, and Hall 2009), and we know that arts teachers in arts-hostile/indifferent schools often try to maintain art broker pedagogical practices. This can be an uphill battle in an arts-hostile educational field and in a school keen to maintain its position in the current field (EBacc, inspection, funding cuts, enrolment and reputational struggles, as we explained earlier). This was also the case for some arts broker teachers in our study. However, most were not experiencing such severe difficulties. They were able to make their arts word disposition into practice - the conditions in the arts rich school field were favourable.

In interviews many of the TALE teachers spoke about the 'fit' between their arts rich school and their own beliefs and practices. Some had chosen the school because of its commitment to the arts; in other instances the school had chosen the teachers because of their practice. The harmonisation of teacher and school is important as it not only demonstrates the correspondences in position between institution and agents, but also points to the ways in which it felt - and was - both 'right' and possible for teachers in arts rich schools to use their art world positional capitals and practices. The logics of the field strategies used by the arts rich school - forming and maintaining a particular identity, developing an explicit philosophy about a broad and balanced curriculum, recruiting students and locating the school in the market on the basis of its arts offer-depended on the 
practices of arts broker teachers. While core subject teachers were responsible for keeping the school in line with audit and test results, arts broker teachers were supported to ensure that the school was well connected with local, regional and national arts organisations and events, and students engaged in ambitious projects that demonstrated their, and their teachers' expertise. The arts cultural capitals of the school were also instantiated through extra curricula activities, excursions and public events.

The arts broker teachers thus not only 'worked' for students but also made their schools arts rich. They translated the cultural goals of the school, animated and made them material, vernacular and specific to the local area and school mix. Reciprocally, the arts rich school recognised and resourced the arts broker practices of the teachers. Together, an internal arts rich school field was produced and reproduced, a field in which the arts had sufficient distinction for students to continue to choose arts subjects in relatively large numbers, despite the external wider field trends in the opposite direction. The higher rates of students' cultural participation in our survey could suggest that at least some of the parents and students chose the school on the basis of overall 'fit', and that the reciprocal field work of school leadership and management strategies and teachers' arts broker dis/positional practices contributed to the school complementarity with primary family habitus capitals.

We now turn as the final move in our argument to consider what this analysis might mean for social justice. Do the arts rich school and the art broker teacher positions and logics of practice simply reproduce hierarchies in the education field and beyond?

\section{Reproducing dis/positions}

Our study suggests that being an arts rich school appears to be a successful field strategy. However, as field success is now dependent on exam results which largely exclude the arts, the onus of maintaining field position falls to other subject teacher positions and practices and management and leadership strategies. The arts per se might perhaps have been more connected to parental aspirations and enrolments than to the official policy game. We do not know if this was the case, as ours was not a study of school choice. But many of the students who were taking arts subjects in senior high school told us that they made this choice against the advice of family and friends. Furthermore, a quarter of students in the survey told us that their school introduced them to the arts, and one third reported that they depended on their school for ongoing arts engagement. We read this as saying that the school itself produced new capitals and dispositions for a significant minority of the surveyed students.

Importantly, only a minority of students in our survey and focus groups intended to go on to work in the creative industries, a highly classed, raced and gendered sub-economic field (Oakley and O'Brien 2015). But almost all of them did intend to continue to engage in the arts. The arts were, the students in focus groups told us, part of the way that they wanted to live their lives. In other words, by the time they were in senior school, students who chose the arts had an art world disposition. Continuing with an arts practice seemed natural and desirable. We can be relatively confident in suggesting that arts brokers teachers did produce a contemporary arts world disposition, in keeping with the overall role of the education field producing capitals and dispositions for other fields. The production of a student arts world disposition was arguably greater in arts rich schools than in others.

This leads us to ask whether the arts rich school was simply inculcating middle class taste, capitals, dispositions and practices. This must to some extent be the case. But, one of the key practices of arts broker teachers was to recognise, seek out, make connections with and promote in the curriculum 
local vernacular cultural practices and local arts and cultural organisations. While schools in poor areas were particularly keen that knowledge and experience of elite cultural institutions was not left to students whose parents could afford to take them there, they did not ignore the students' own everyday cultural practices and their particular arts interests. They were also often keen to include youth cultural practices in the formal curriculum. The approach to both the visual and performing arts curriculum was more 'omnivore' than partial: Shakespeare and rap, three dimensional objects and Instagram and so on.

The 'omnivore' is arguably now the constellation of cultural capitals that dominate the cultural industries and the marketised arts and culture field (Friedman 2012; Peterson and Kern 1996). But arts broker teachers did not simply reproduce this elite omnivorous art field disposition. They did not, as we have said, simply produce arts consumers and artists destined for employment in the creative industries. Because teachers saw all students as artists, all students were seen as capable of critical and reflective practice. In the performing arts, students were encouraged through rehearsal room approaches and dramaturgical and directorial practices to see a Shakespearian text as socially constructed, as an elite art form which nevertheless raised important questions about power and the workings of social institutions. In the visual arts, students were encouraged to focus on the ways in which the world worked, the art world functioned and their position in it. In both art forms, and in keeping with arts brokers teachers' art field dispositions, students were encouraged to be reflective and reflexive about their own positioning and practices. We suggest therefore that the arts broker practice was one which was not simply reproductive, but also produced reflexive counter arts-field resources - capitals and strategies.

Importantly, within the school, be it arts rich or not, the practices associated with the arts broker teacher position also showed that there were pedagogical logics other than those necessary for passing high stakes tests. Arts field practices and capitals sat alongside dominant education field practices (c.f. Adams 2010); arts brokerage pedagogies worked counter to dominant education field doxa of 'knowledge-based' teaching, lesson by lesson target-driven progression, and narrow assessment oriented learning. Students and teachers used and acquired different capitals and dispositions, perhaps more democratically oriented. The doxa of cultural rights, dominant in the arts field, spoke against the economistic human capital doxa dominant in the education field and thus supported struggles against simple reproduction via dominant pedagogical practices. While this did not necessarily create tension within the schools, there was nevertheless a reservoir of alternative practice that might be used more widely if conditions in the wider education and political field were to change.

\section{In sum}

Our intention in this paper has been to theorise dual field occupancy, using data from a study of arts rich schools (a field position) and arts broker teachers (an internal school field position) with an arts world disposition and capitals. We argued that the correspondence and reciprocity of arts rich school and arts broker teacher positions (re)produced particular art world dispositions in students. We concluded that while arts brokerage logics of practice could be seen as reproductive, this was not simply the case, as they were also partially oppositional. As such, arts rich schools and arts broker teachers might form part of the basis for change in the field, although this is highly dependent on change in the wider education and political fields.

The implications of this analysis are both theoretical and practical. We hope to have demonstrated the potential of Bourdieu's theory to illuminate practices which might support field change. Rather than focus on reproduction per se, the study shows how the correspondence between school and teacher working together produces a 'strategy reservoir' of practical pedagogical resources that 
have potential for wider take up. This also suggests that further work on field positions, using different data sets, might be of value. Practically, the study also shows the potential for teacher education and teacher professional development which mobilises teacher dual field positioning, where it exists. We think for instance of English teachers who read and write, Science teachers engaged in citizen science activities, History teachers involved in local history groups and so on. In addition to recognising dispositions from teachers' primary habitus, our study and theorisation points to possible field benefits from taking a more holistic approach to teachers and teaching.

\section{References}

Adams, Jeff. 2010. "Risky choices: the dilemmas of introducing contemporary art ptactice into schools." British Journal of Sociology of Education 31 (6):683-701.

Adams, Michael. 2006. "Hybridizing habitus and reflexivity: Towards an understanding of contemporary identity?" Sociology 40 (3):511-28.

Apple, Michael. 2001. Educating the "right" way. Markets, standards, God and inequality. New York \& London: Routledge Falmer.

Ball, Stephen. 2003. Class strategies and the education market. The middle classes and social advantage. London: Routledge Falmer.

- - . 2018. The education debate. third ed. Bristol: The Policy Press.

Ball, Stephen, and Carolina Junemann. 2012. Networks, new governance and education. Bristol: Policy Press.

Beane, James. 1995. "Curriculum integration and the disciplines of knowledge." Phi Delta Kappan 76:616-22.

Boomer, Garth, Nancy Lester, Cynthia Onore, and Jon Cook. 1992. "Negotiating the curriculum. Educating for the twenty first century." In. London: Falmer.

Bourdieu, Pierre. 1975. "The specifity of the scientific field and the social conditions of the progress of reason." Sociology of Science 14 (6):19-47.

- - . 1977. Outline of a theory of practice. Cambridge: Cambridge University Press.

- - . 1987. "The biographical illusion." Working Papers and Proceedings of the Centre for Psychosocial Studies (University of Chicago) 14:1-7.

- - - 1988. Homo academicus. Translated by Peter Collier. Stanford, California: Stanford University Press.

-- - 1990. In other words. Essays towards a reflexive sociology. Stanford, California: Stanford University Press.

-- - 1991. The love of art: European art museums and their public. Translated by C Beattie and N Merriman. Cambridge: Polity Press.

-- - 1992. The rules of art. Genesis and structure of the literary field. Translated by Susan Emanuel. Stanford, CA: Stanford University Press.

- - . 1998. Practical reason. On the theory of action. Oxford: Blackwell.

Bourdieu, Pierre, and Jean Claude Passeron. 1977. Reproduction in society, education and culture. London: Sage.

- - . 1979. The inheritors, French students and their relation to culture. Chicago: The University of Chicago Press.

Bourdieu, Pierre, and Loic Wacquant. 1992. An invitation to reflexive sociology. Chicago and London: University of Chicago Press.

Fecho, Bob. 2011. Writing in the dialogical classroom. Students and teachers responding to the texts of their lives. Urbana, ILL: National Council of Teachers of English.

Franks, Anton, Pat Thomson, Christine Hall, and Ken Jones. 2014. "Teachers, arts practice and pedagogy." Changing English 21 (2):171-81.

Friedman, Sam. 2012. "Cultural omnivores or culturally homeless? Exploring the shifting cultural identities of the upwardly mobile." Poetics 40 (5):467-89. 
Gorard, Stephen. 2018. "Grammar schools in Engliand: a new analysis of social segregation and academic outcomes." British Journal of Sociology of Education:DOI:

10.1080/01425692.2018.1443432.

Ingram, Nicola, and Jessica Abrahams. 2016. "Stepping outside oneself: how a cleft habitus can lead to greater reflexivity through occupyng "third space"." In Bourdieu: the next generation. The development of Bourdieu's intellectual heritage in contemporary UK sociology, edited by Jenny Thatcher, Nicola Ingram, Ciaran Burke and Jessie Abrahams. London: Routledge.

Jezewski, M.A. 1995. "Evolution of a grounded theory: Conflict resolution through culture brokering." Advances in Nursing Science 17 (3):14-30.

Johnes, Rebecca. 2017. Entries to arts subjects at Key Stage 4. London: Education Policy Insttitute. Lillis, Theresa, and Mary Jane Curry. 2010. Academic writing in a global context. The politics and practices of publishing in English. London: Routledge.

Lingard, Bob, and Sean Rawolle. 2004. "Mediatising education policy: The journalistic field, science policy and cross-field effects." Journal of Education Policy 19 (6):353-72.

---. 2013. Bourdieu and the field of education policy. Understanding globalisation, mediatisation, implementation. London: Routledge.

McKinley, Elizabeth. 2001. "Cultural diversity: Masking power with innocence." Science Education 85 (1):74-6.

Neelands, Jonathon. 2009. "Acting together: ensemble as a democratic process in art and life." Research in Drama Education 14 (2):173-89.

Oakley, Kate, and David O'Brien. 2015. Cultural value and inequality. A critical literature review. Swindon: Arts and Humanities Research Council.

Peterson, R, and R Kern. 1996. "Changing "highbrow" taste: From snob to omnivore." American Sociological Review 61 (5):900-7.

Power, Sally, Tim Edwards, Geoff Whitty, and V Wigfall. 2002. Education and the middle classes. Buckingham: Open University Press.

Reay, Diane. 2004. "'It's all becoming a habitus':beyond the habitual use of habitus in educational research." British Journal of Sociology of Education 25 (4):431-44.

Reay, Diane, Miriam David, and Stephen Ball. 2005. Degrees of choice. Class, race, gender and higher education. Stoke on Trent: Trentham.

Stahl, Garth. 2013. "Habitus disjunctures, reflexivity and white working class boys' conceptions of status in learner and status identities." Sociological Research Online 18

(3):http://www.socresonline.org.uk/18/3/2.html.

Thomson, Pat, Christine Hall, Lexi Earl, and Corinna Geppert. 2018. "Time to listen." In. researchtale.net: RSC, TATE, University of Nottingham.

- - . 2019. "Subject choice as everyday accommodation/resistance: Why students in England (still) choose the arts." Critical Studies in Education:doi.org/10.1080/17508487.2018.1525754.

Thomson, Pat, Ken Jones, and Christine Hall. 2009. Creative whole school change. Final report. London: Creativity, Culture and Education; Arts Council England. .

Thomson, Pat, and Barbara Kamler. 2013. Writing for peer reviewed journals: strategies for getting published. London: Routledge.

Wilkins, Andrew. 2011. "School choice and the commodification of education: a visual approach to school brochures and wesbites." Critical Social Policy 32 (1):69-86.

Willis, E. 1999. "From cultural brokers to shared care: The changing position of literacy for Aboriginal health workers in Central Australia." Studies in Continuing Education 221 (2):163-75.

Wyatt, J.D. 1978-79. "Native involvement in curriculum development: The Native teacher as cultural broker." Interchange 9 (1):17-28. 